\title{
Comparative efficacies and durations of action of phenoxybenzamine, verapamil/nitroglycerin solution, and papaverine as topical antispasmodics for radial artery coronary bypass grafting
}

\author{
Shafi Mussa, MA, MRCS ${ }^{a, b}$ \\ Tomasz J. Guzik, MD, PhD ${ }^{\text {b }}$ \\ Edward Black, FRCS ${ }^{a}$ \\ Michelle A. Dipp, DPhil \\ Keith M. Channon, MD, MRCPb \\ David P. Taggart, MD, PhD, FRCS ${ }^{a}$
}

\footnotetext{
From the Department of Cardiothoracic Surgery, John Radcliffe Hospital, ${ }^{a}$ and the Department of Cardiovascular Medicine, ${ }^{\text {b }}$ University of Oxford, Oxford, United Kingdom.

Supported by the British Heart Foundation. S.M. is a British Heart Foundation Junior Research Fellow (FS2001052). K.M.C. is supported by grants from the British Heart Foundation and the Oxfordshire Health Services Research Committee.

Received for publication Sept 9, 2002; revisions requested Oct 2, 2002; revisions received Nov 12, 2002; accepted for publication March 25, 2003.

Address for reprints: David P. Taggart, MD, PhD, FRCS, Consultant Cardiothoracic Surgeon, John Radcliffe Hospital, Headley Way, Headington, Oxford OX3 9DU, United Kingdom (E-mail: david.taggart@orh.nhs.uk).

J Thorac Cardiovasc Surg 2003;126: 1798-805

Copyright $\odot 2003$ by The American Association for Thoracic Surgery

$0022-5223 / 2003 \$ 30.00+0$

doi:10.1016/S0022-5223(03)00943-7
}

Objective: Radial arteries are increasingly used as conduits for coronary artery bypass grafts, but perioperative graft vasospasm continues to be a concern. Phenoxybenzamine, verapamil/nitroglycerin solution, and papaverine have been advocated as topical antispasmodic agents. We compared the relative efficacies and durations of action of these agents.

Methods: Isometric tension developed in response to clinically important vasoconstrictors was measured in 100 radial artery rings (from patients undergoing coronary artery bypass grafting, $\mathrm{n}=25$ ) after 15 minutes of ex vivo incubation with phenoxybenzamine, verapamil/nitroglycerin solution, papaverine, or vehicle (control). Duration of action was assessed by measuring responses to vasoconstrictors in antispasmodic pretreated and control rings at intervals through 5 hours.

Results: Verapamil/nitroglycerin solution reduced vasoconstriction in response to epinephrine, angiotensin II, prostaglandin $\mathrm{F}_{2 \alpha}$, and phenylephrine but its effect had almost completely waned after 5 hours. Phenoxybenzamine prevented vasoconstriction in response to epinephrine, dopamine, and phenylephrine, with its effect lasting at least 5 hours. Papaverine had limited antispasmodic efficacy and prevented vasoconstriction in response to potassium $(60 \mathrm{mmol} / \mathrm{L})$ and phenylephrine for only 1 hour at the longest.

Conclusions: Verapamil/nitroglycerin solution has a broad efficacy against a range of vasoconstrictors but a limited duration of action. Papaverine has the shortest duration of action. Phenoxybenzamine is an effective agent with a prolonged duration of action, specifically preventing catecholamine mediated vasospasm of radial artery conduits.

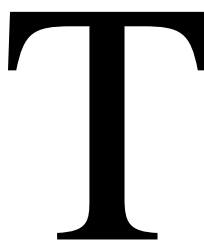

he increasing use of multiple arterial conduits in coronary artery bypass grafting (CABG) has followed the superior results initially achieved with a single internal thoracic artery (ITA) ${ }^{1}$ and more recently with bilateral ITAs. ${ }^{2,3}$ Most patients undergoing CABG need three or more grafts, and the radial artery has become the conduit of choice for the third graft. ${ }^{4}$ First used as an aorta-coronary graft in 1971,5 it was subsequently abandoned because of high rates $(35 \%)$ of 
postoperative narrowing or occlusion on angiography. Interest in the radial artery has been rekindled ${ }^{6}$ because it can be harvested easily and safely, reaches any coronary target comfortably, and can be used as either free or composite grafts. ${ }^{4}$ Five-year patency rates between $85 \%^{7}$ and $92 \%$ have been reported. Despite its attractive handling characteristics and improvements in harvesting technique, however, perioperative graft vasospasm continues to be a major concern. ${ }^{6}$

The radial artery is a thick-walled, predominantly muscular artery with a mean medial width of $500 \mu \mathrm{m}$, compared with $300 \mu \mathrm{m}$ for the more elastic ITA. ${ }^{9}$ The radial artery has a greater contractility than the ITA, ${ }^{10}$ but the value appears to be equivalent to that of the ITA when corrected for vessel diameter. Ex vivo studies have demonstrated that substances such as endothelin I, angiotensin II, ${ }^{11}$ norepinephrine, serotonin, and thromboxane $\mathrm{A}_{2}$ cause greater vasoconstriction in the radial artery than the ITA, ${ }^{12}$ suggesting that the propensity toward spasm is not solely a function of the muscular wall but that an enhanced reactivity to vasoactive mediators is of key importance. ${ }^{11}$ The circulating levels of many of these substances are increased during and after cardiac surgery. ${ }^{13}$ In arterial conduits the predominant receptors responsible for these effects are $\alpha$-adrenergic, thromboxane-prostanoid, and endothelin (types A and B) receptors. $^{14}$

Several topical and systemic pharmacologic preparations have been used to reduce radial artery graft vasospasm. Ideally, antispasmodic preparations should prevent vasoconstriction in response to relevant contractile stimuli for a prolonged period (throughout the postoperative period) without damaging the conduit and while avoiding systemic hemodynamic effects. Topical agents are especially attractive because they are easily administered during surgery and do not have systemic hemodynamic effects. Because repeated application is not possible after chest closure, duration of action is of particular importance. Papaverine, ${ }^{15}$ verapamil/nitroglycerin solution (VG solution), ${ }^{16}$ and phenoxybenzamine are in clinical use as topical radial artery antispasmodic agents. However, the relative merits and weaknesses of these preparations in modulating radial artery graft vasospasm are poorly defined. We therefore systematically compared these agents by examining their effects on a range of contractile stimuli in human radial artery and their durations of action.

\section{Methods}

\section{Patients and Vessel Preparation}

Ethical approval was given by the local research ethics committee (OxREC C01.207). Radial artery specimens were obtained after written informed consent from patients $(\mathrm{n}=25)$ undergoing total arterial CABG. Patient demographic characteristics, numbers undergoing urgent surgery, risk factors for atherosclerosis, and preoperative medications are shown in Table 1. The radial artery was

\section{TABLE 1. Patient clinical characteristics}

\begin{tabular}{lr}
\hline Age (y, mean \pm SEM) & $62 \pm 2.0$ \\
Sex (male/female ratio) & $21: 4$ \\
Urgent operation & $11(44 \%)$ \\
Risk factors (No.) & \\
Smoking & $5(20 \%)$ \\
Hypertension & $19(76 \%)$ \\
Diabetes mellitus & $8(32 \%)$ \\
Hypercholesterolemia & $23(92 \%)$ \\
Medication (No.) & \\
$\beta$-Blocker & $18(72 \%)$ \\
Calcium-channel antagonist & $13(52 \%)$ \\
Nitrate & $9(36 \%)$ \\
Angiotensin-converting enzyme inhibitor* & $9(36 \%)$ \\
Lipid-lowering agent & $24(96 \%)$ \\
Potassium-channel opener & $3(12 \%)$ \\
Diuretic & $5(20 \%)$ \\
\end{tabular}

*Includes patients receiving angiotensin II blockers.

harvested with accompanying venae comitantes and connective tissue intact, and a 1.5- to $2-\mathrm{cm}$ segment was obtained from the distal end and placed immediately in cold $\left(4^{\circ} \mathrm{C}\right)$ Krebs-Henseleit buffer solution $(\mathrm{KHB} ; 120-\mathrm{mmol} / \mathrm{L}$ sodium chloride, $4.7-\mathrm{mmol} / \mathrm{L}$ potassium chloride, $1.2-\mathrm{mmol} / \mathrm{L}$ magnesium sulfate, $1.2-\mathrm{mmol} / \mathrm{L}$ potassium phosphate, $2.5-\mathrm{mmol} / \mathrm{L}$ calcium chloride, $25-\mathrm{mmol} / \mathrm{L}$ sodium hydrogen carbonate, $5.5-\mathrm{mmol} / \mathrm{L}$ glucose). The arterial segment was carefully dissected free of its adnexae and cut into four vascular rings, each measuring $3 \mathrm{~mm}$ in length.

\section{Vasomotor Studies}

Isometric tension studies were performed by mounting vascular rings on stainless steel hooks in $25-\mathrm{mL}$ organ chambers containing warm $\left(37^{\circ} \mathrm{C}\right) \mathrm{KHB}$, constantly aerated with $95 \%$ oxygen and $5 \%$ carbon dioxide. After 30 minutes of equilibration, all rings underwent incremental passive stretching to achieve a steady resting tension of $3 \mathrm{~g}$. All contractile responses were measured from rings at 3-g steady resting tension, which had been determined as optimal in preliminary experiments. All experiments were conducted in the presence of $10-\mu \mathrm{mol} / \mathrm{L}$ indomethacin (Sigma, St Louis, Mo) to inhibit prostanoid synthesis.

The maximum developed tension in response to the addition of warm $\left(37^{\circ} \mathrm{C}\right)$, aerated $(95 \%$ oxygen and $5 \%$ carbon dioxide) modified $\mathrm{KHB}$ containing $60-\mathrm{mmol} / \mathrm{L}$ potassium ion $(64.7-\mathrm{mmol} / \mathrm{L}$ sodium chloride, $58.8-\mathrm{mmol} / \mathrm{L}$ potassium chloride, $1.2-\mathrm{mmol} / \mathrm{L}$ magnesium sulfate, $1.2-\mathrm{mmol} / \mathrm{L}$ potassium phosphate, $2.5-\mathrm{mmol} / \mathrm{L}$ calcium chloride, $25-\mathrm{mmol} / \mathrm{L}$ sodium hydrogen carbonate, 5.5$\mathrm{mmol} / \mathrm{L}$ glucose) was measured in each ring. Each ring was then incubated for 15 minutes with either phenoxybenzamine (10 $\mu \mathrm{mol} / \mathrm{L}$; Goldshield Pharmaceuticals Ltd, Croydon, United Kingdom), VG solution consisting of a verapamil (Knoll Pharmaceuticals, Mount Olive, NJ) and nitroglycerin (Schwarz Pharma, Monheim, Germany) mixture $\left(30 \mu \mathrm{mol} / \mathrm{L}\right.$ each $\left.{ }^{16}\right)$, or papaverine $(266$ $\mu \mathrm{mol} / \mathrm{L}$ or $0.1 \mathrm{mg} / \mathrm{mL}$, Sigma). The remaining ring was left untreated as a control.

The rings were washed after 15 minutes to remove excess antispasmodic agent from the organ chambers. After 10 minutes of equilibration, the response to modified KHB $(60-\mathrm{mmol} / \mathrm{L}$ potassium ion) was measured again. Cumulative dose responses to 

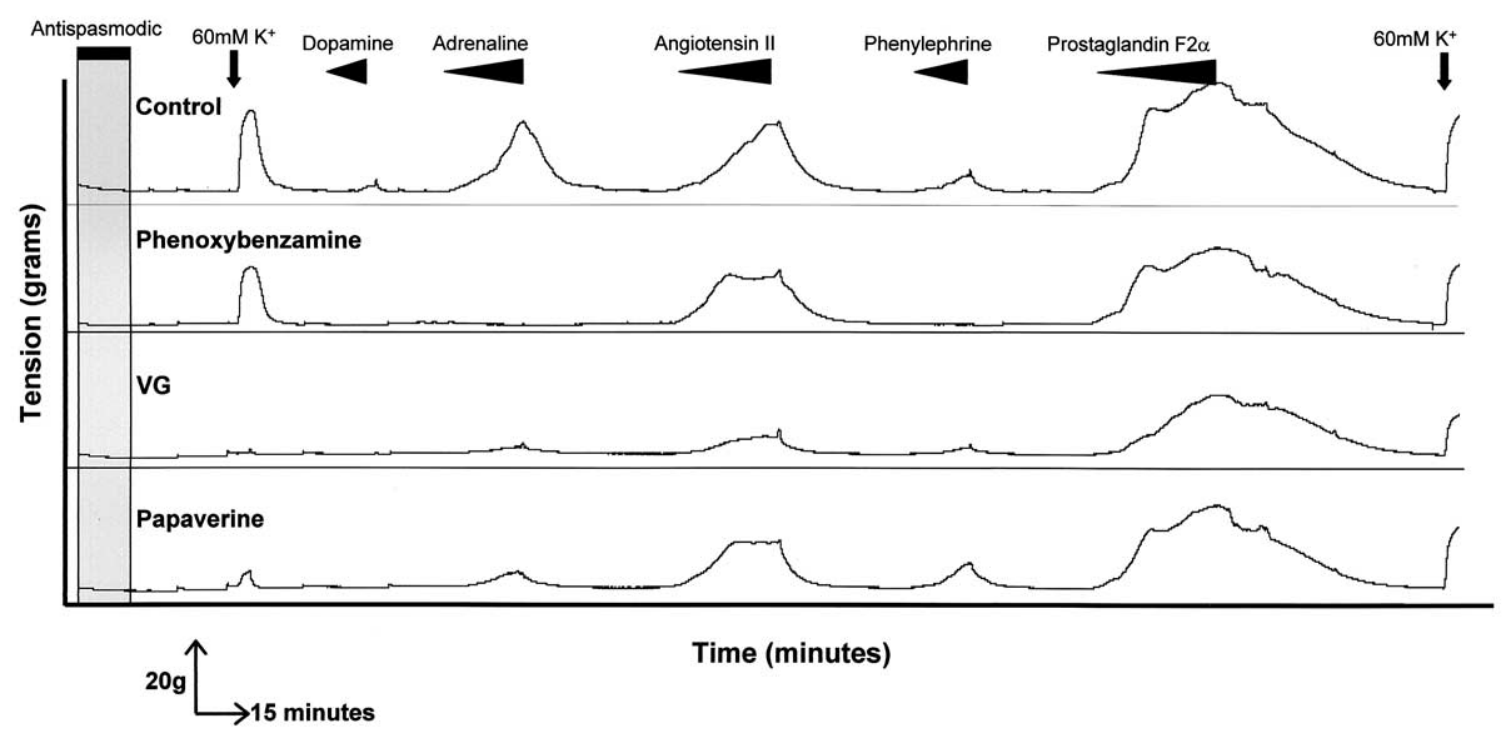

Time (minutes)

Figure 1. Representative data from 4 radial artery rings ( $n=1$ patient) illustrating experimental protocol. Isometric tension studies of vascular rings suspended in organ chambers. Rings were incubated for 15 minutes with phenoxybenzamine, VG solution, papaverine, or vehicle (control, gray bar). Contractile responses (tension in grams) to $60-\mathrm{mmol} / \mathrm{L}$ potassium ion (heavy arrows) and serial cumulative additions of dopamine, epinephrine, angiotensin II, phenylephrine, and prostaglandin $F_{2 \alpha}$ (solid triangles) were measured while time elapsed from initial exposure to antispasmodic agents was noted.

epinephrine (1-nmol/L to 10- $\mu \mathrm{mol} / \mathrm{L} ;$ Sigma), angiotensin II (10$\mathrm{pmol} / \mathrm{L}$ to $100-\mathrm{nmol} / \mathrm{L}$; Sigma), phenylephrine (1-nmol/L to 10 $\mu \mathrm{mol} / \mathrm{L} ;$ Sigma), prostaglandin $\mathrm{F}_{2 \alpha}$ (1-nmol/L to $10-\mu \mathrm{mol} / \mathrm{L}$; Sigma), and dopamine (10-nmol/L to $100-\mu \mathrm{mol} / \mathrm{L}$; Martindale Pharmaceuticals Ltd, Brentwood, United Kingdom) were then measured serially in each ring.

Between successive vasoconstrictor applications, each ring was washed twice with warm, aerated KHB, allowed to re-equilibrate, and stretched passively to achieve a steady resting tension of $3 \mathrm{~g}$. The time elapsed from treatment with antispasmodic agents was noted for each vasoconstrictor addition in each ring. In subsequent experiments, the order of addition of the five vasoconstrictors was systematically rotated according to a cyclic scheme, enabling measurement of the duration of action of each antispasmodic agent versus each vasoconstrictor. Finally, the response to modified KHB (60-mmol/L potassium ion) was measured. The protocol is illustrated by raw data from a representative experiment (Figure 1).

\section{Statistical Analysis}

Contractile responses were expressed as a percentage of the initial response to modified $\mathrm{KHB}$ (60-mmol/L potassium ion) in individual rings. Data are shown as mean \pm SEM. Dose-response curves were compared with control values by means of a general linear model for repeated measures (SPSS for Windows 10.0; SPSS Inc, Chicago, Ill). Two-tailed Student $t$ tests were used to compare receptor-independent responses and the maximal responses at each time point with their respective control values.

\section{Results}

Efficacy of Antispasmodic Activity

To determine the relative efficacies of the antispasmodic agents against a range of vasoconstrictors, radial artery rings were incubated with either phenoxybenzamine, VG solution, papaverine, or vehicle (control) for 15 minutes. The isometric tension developed in response to increasing concentrations of epinephrine, angiotensin II, phenylephrine, prostaglandin $\mathrm{F}_{2 \alpha}$, and dopamine was then measured serially in each ring (Figure 2). VG solution significantly reduced contractile responses to epinephrine, angiotensin II, phenylephrine, and prostaglandin $\mathrm{F}_{2 \alpha}$ but did not affect contractions to dopamine. Incubation of vessel rings with phenoxybenzamine prevented contractions to epinephrine, dopamine, and phenylephrine but not prostaglandin $\mathrm{F}_{2 \alpha}$; contractile responses to angiotensin II were modestly augmented at concentrations greater than $1 \mathrm{nmol} / \mathrm{L}$. In contrast, papaverine pretreatment resulted in no significant differences in contractile responses to any vasoconstrictor relative to control rings. These findings suggest that phenoxybenzamine has a specific action against $\alpha$-adrenergic-mediated radial artery constriction, whereas $\mathrm{VG}$ solution has activity against a broader range of vasoconstrictive agents.

\section{Duration of Antispasmodic Effect}

Receptor-independent vasoconstriction. To investigate the duration of activity of each antispasmodic agent, recep- 

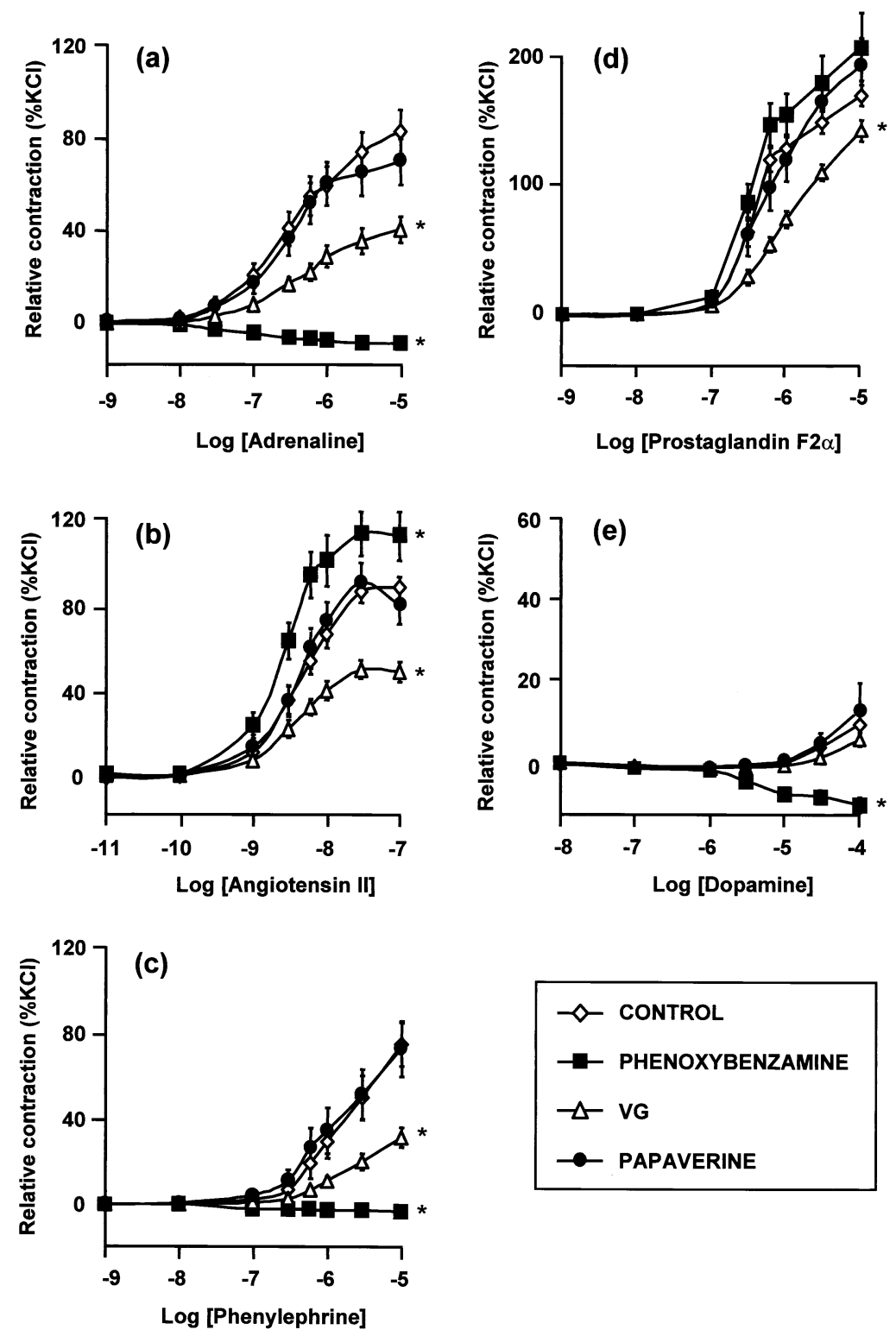

Figure 2. Effects of antispasmodic pretreatment on receptor-mediated contractile response ( $n=25$ patients). Isometric tension studies of vascular rings incubated for 15 minutes with phenoxybenzamine (filled squares), VG solution (open triangles), and papaverine (filled circles) were used to measure cumulative dose responses to epinephrine (A), angiotensin II (B), phenylephrine (C), prostaglandin $F_{2 \alpha^{\prime}}$ and dopamine (E). Untreated rings were controls (open diamonds). Data points represent mean \pm SEM contractile responses expressed relative to response to $60-\mathrm{mmol} / \mathrm{L}$ potassium ion in individual rings before incubation with antispasmodic agents. For clarity, dose responses to prostaglandin $F_{2 \alpha}$ and dopamine are shown on enlarged and reduced scales, respectively. Asterisks indicate $\boldsymbol{P}<.05$ versus controls.

tor-independent contractile responses to $60-\mathrm{mmol} / \mathrm{L}$ potassium ion in antispasmodic-treated and -untreated (control) rings were measured at two time points 5 hours apart (Figure 3). VG solution virtually abolished the early contractile response. Contractile activity had almost fully returned by the late time point, showing that the effect of VG solution was in large part lost after 5 hours. Similarly, papaverine pretreated vessel rings contracted minimally in response to $60-\mathrm{mmol} / \mathrm{L}$ potassium ion at the early time point but exhibited a greater contractile response than control preparations 5 hours later. Thus the antispasmodic effect of papaverine failed to last 5 hours. Phenoxybenzamine incu- 


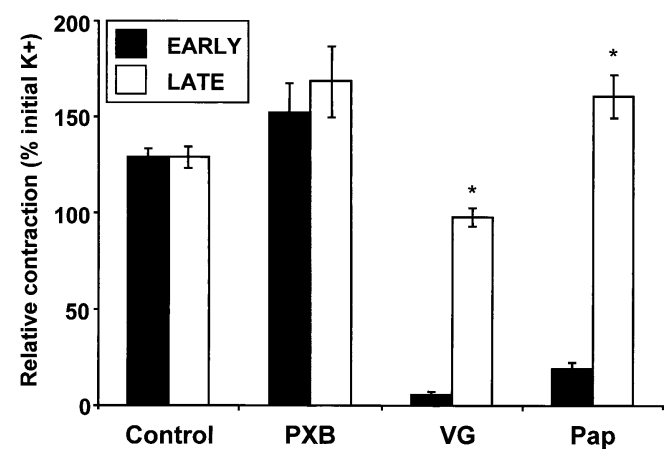

Figure 3. Durations of antispasmodic effects against receptorindependent vasoconstriction. Isometric tension studies of radial artery rings ( $\mathrm{n}=22$ patients) incubated for 15 minutes with phenoxybenzamine (PXB), VG solution (VG), or papaverine (Pap). Control rings were incubated with vehicle only. Contractile responses to $60-\mathrm{mmol} / \mathrm{L}$ potassium ion were then measured at early (filled bars, $0.52 \pm 0.02$ hours) and late (open bars, $5.64 \pm 0.14$ hours) time points. Bars represent mean \pm SEM contractile responses expressed relative to response to $60-\mathrm{mmol} / \mathrm{L}$ potassium ion in individual rings before incubation with antispasmodic agents. Asterisks indicate $\boldsymbol{P}<.05$ versus responses at early time points.

bation had no effect on potassium-mediated contraction at either time point, providing further evidence for its specificity of action against the $\alpha$-adrenergic system.

Receptor-mediated vasoconstriction. Next, the durations of antispasmodic activity against specific receptormediated vasoconstrictors were examined (Figure 4). We measured the isometric tension developed by antispasmodic-treated radial artery rings during a systematic protocol of serial contractions with a rotating allocation of vasoconstrictors, interspersed with a defined series of washes, through a period of more than 5 hours. For analysis, contractions to maximum concentrations of vasoconstrictors were used and data were grouped into early $(1.2 \pm 0.04$ hours), mid (3.2 \pm 0.1 hours), and late (5.2 \pm 0.1 hours) time points.

VG solution significantly attenuated the contractile response to phenylephrine, prostaglandin $\mathrm{F}_{2 \alpha}$, and angiotensin II up to the early, mid, and late time points, respectively. Contractility in response to dopamine was unaffected by VG solution at any time. The late response to epinephrine was reduced in VG solution-pretreated rings. Contractile responses to most vasoconstrictors were greater at the late time point in VG solution-treated rings, providing further evidence for a loss in antispasmodic efficacy through a 5-hour period. Phenoxybenzamine abolished the contractile responses to both epinephrine and phenylephrine up to the late time point. A similar pattern was seen in those rings exposed to dopamine, but only the response at the early time point reached statistical significance. In contrast, responses to angiotensin II and prostaglandin $\mathrm{F}_{2 \alpha}$ were not altered by phenoxybenzamine treatment at any time point. Papaverine treatment reduced the contractile response to phenylephrine at the early time point but had no significant effect against any other agonist at any other time point.

\section{Discussion}

The most important findings in this study were as follows:

1. VG solution prevented vasoconstriction mediated by most of the contractile agonists used but was ineffective after 5 hours.

2. Phenoxybenzamine was highly effective in preventing $\alpha$-adrenergic-mediated vasoconstriction for at least 5 hours, but this action was specific and did not extend to other vasoactive mediators.

3. The antispasmodic effect of papaverine was limited to approximately 1 hour duration only.

\section{Strengths}

Major strengths of this work include the direct comparison of three currently used topical antispasmodic agents in 100 radial artery rings from 25 patients undergoing CABG. This is the largest systematic study of this kind to date.

Second, we chose to study a range of vasoconstrictors with direct clinical importance. Cardiopulmonary bypass and surgical stress cause immediate 20 -fold elevations in plasma levels of epinephrine, to concentrations similar to those used in this study, and elevations remain until at least a day after surgery. ${ }^{17}$ Epinephrine infusions are used in the management of low cardiac output states, further increasing the circulating levels of this vasoconstrictor. Similarly, angiotensin II levels after cardiopulmonary bypass have been measured at $0.2 \mathrm{nmol} / \mathrm{L} .{ }^{18}$ Plasma levels of dopamine are not consistently elevated after cardiopulmonary bypass, but the agent may be administered intravenously as a pressor after cardiac surgery. ${ }^{13}$ Prostaglandin $\mathrm{F}_{2 \alpha}$ is a potent vasoconstrictor of arterial conduits. ${ }^{14}$

\section{Interpretation}

VG solution, a mixture of verapamil (a highly selective voltage-dependent calcium-channel antagonist with a plasma half-life of up to 4.8 hours $^{19}$ ) and nitroglycerin (a nitric oxide donor with a short half-life) was first suggested by $\mathrm{He}$ and colleagues ${ }^{20,21}$ for saphenous vein and ITA conduit preparation. The same authors subsequently demonstrated vasodilatation in response to VG solution applied to radial artery rings precontracted with potassium chloride $^{16}$ and reported that the effect persisted for at least 24 hours in radial artery segments stored for 24 hours at $4^{\circ} \mathrm{C}$. Whereas our study confirms that VG solution virtually eliminates receptor independent vasoconstriction $30 \mathrm{~min}$ utes after incubation and is also effective against adrenergic, thromboxane, prostanoid, and angiotensin mediated vaso- 

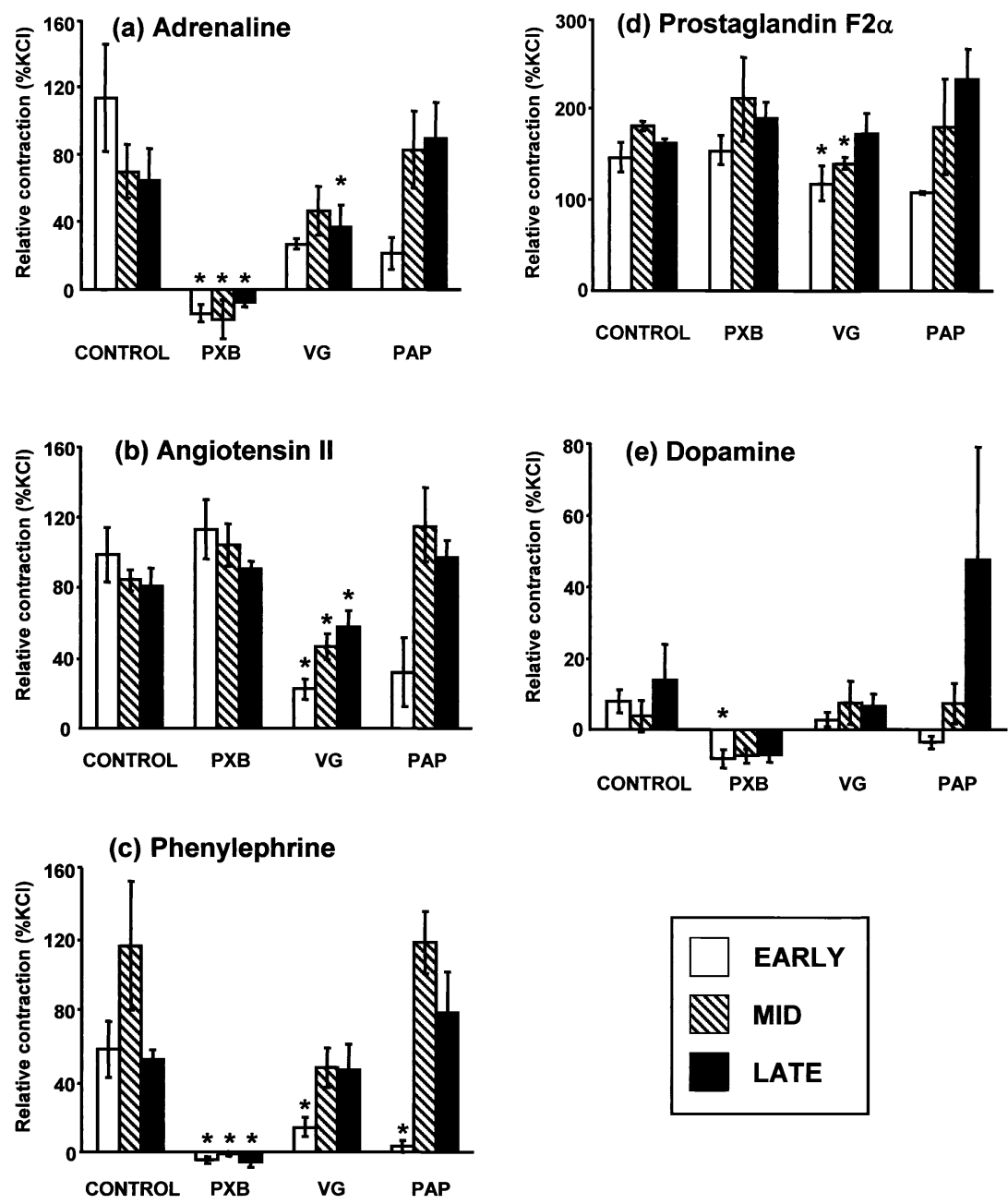

Figure 4. Durations of antispasmodic effects against receptor-mediated vasoconstriction. Isometric tension studies of radial artery rings incubated for 15 minutes with phenoxybenzamine (PXB), VG solution (VG), or papaverine $(P A P)$. Control rings were incubated with vehicle only. Bars represent mean \pm SEM contractile responses to 10-mmol/L epinephrine (A), 100-mmol/L angiotensin II (B), 10-mmol/L phenylephrine (C), 10-mmol/L prostaglandin $F_{2 \alpha}(D)$, and $100-\mathrm{mmol} / \mathrm{L}$ dopamine $(E)$ in control (untreated) and antispasmodic-pretreated vascular rings. Contractile responses (expressed relative to response to $60-\mathrm{mmol} / \mathrm{L}$ potassium ion in individual rings before incubation with antispasmodic agents) were measured at $1.2 \pm 0.04$ hours (EARLY, white bars), $3.2 \pm 0.1$ hours (MID, shaded bars), and $5.2 \pm 0.1$ hours (LATE, black bars) after antispasmodic pretreatment. For clarity, responses to prostaglandin $F_{2 \alpha}$ and dopamine are shown on enlarged and reduced scales, respectively. At each time point 3 to 5 vascular rings were measured. Asterisks indicate $P<.05$ versus time-matched controls.

constriction, we found that the effect was largely lost within 5 hours. Certain aspects of our experimental protocol may explain the difference in the durations of action reported by ourselves and by $\mathrm{He}$ and colleagues. ${ }^{16}$ First, our radial artery segments were exposed to the antispasmodic agents for 15 minutes, rather than the 45 minutes recommended by $\mathrm{He}$ and colleagues, ${ }^{16}$ because longer exposure is often impractical in the operating room. Second, the storage of VG solution-treated rings for 24 hours at $4^{\circ} \mathrm{C}$ does not reflect the clinical situation.
In recent years there has been considerable interest in the use of phenoxybenzamine as a topical antispasmodic for radial artery conduit preparation. It is a nonselective $\alpha$-adrenoceptor antagonist, with a long duration of action resulting from alkylation of the target receptors. Our group initially reported the efficacy of phenoxybenzamine versus epinephrine-mediated vasoconstriction in the radial artery ${ }^{22}$ and noted that it does not cause endothelial dysfunction. ${ }^{23}$ Its efficacy in preventing norepinephrine-mediated vasoconstriction has been clearly demonstrated. ${ }^{24}$ Recent contribu- 
tions to the literature suggest reductions in dose and treatment time and have found the ex vivo durations of action of phenoxybenzamine in preventing catecholamine-mediated vasoconstriction to be variously 18 hours $^{24}$ and 48 hours. ${ }^{25}$

This study used a low dose $(10 \mu \mathrm{mol} / \mathrm{L})$ and a clinically relevant treatment time (15 minutes) to confirm that phenoxybenzamine abolishes $\alpha$-adrenoceptor-mediated vasoconstriction in human radial artery for at least 5 hours. To achieve these effects in the clinical setting, we recommend the immersion of the harvested radial artery in $100 \mathrm{~mL}$ heparinized blood containing $4 \mathrm{mg}$ phenoxybenzamine.

In addition, this study extends the physiologic understanding of the action of dopamine in phenoxybenzamine pretreated radial artery conduits, with vasorelaxation observed in response to dopamine concentrations of $1 \mu \mathrm{mol} / \mathrm{L}$ and above. In the peripheral vasculature the effects of dopamine are mediated by $\mathrm{D}_{1}$ and $\alpha$-adrenoceptors, with resultant vasodilatation and vasoconstriction, respectively. ${ }^{26}$ Blockade of $\alpha$-adrenoceptors may unmask its $\mathrm{D}_{1}$-mediated effects. Although the contractile response to dopamine was small compared with those of other agonists, this may contribute to the pathogenesis of vasospasm in arterial conduits. The ability to prevent dopamine-mediated vasoconstriction increases the safety of using radial artery conduits in CABG.

The second novel finding is the increased contractility in response to angiotensin II in phenoxybenzamine pretreated radial arteries. Angiotensin II is a potent vasoconstrictor at low concentrations, and its effects are mediated by the G-protein-linked $\mathrm{AT}_{1}$ receptor. ${ }^{27} \alpha$-Adrenoceptors are also G-protein coupled and may share components of intracellular signaling cascades with $\mathrm{AT}_{1}$ receptors. ${ }^{28}$ Interactions between $\alpha_{1}$-adrenoceptors and $\mathrm{AT}_{1}$ receptors have been demonstrated in rat vascular smooth muscle cells, ${ }^{29}$ and blockade of $\alpha$-adrenoceptors may enhance the contractile response to angiotensin II. It is postulated that receptor recycling results in up-regulation of angiotensin receptors or prevents direct cross talk between $\mathrm{AT}_{1}$ receptors and $\alpha$-adrenoceptors. Although phenoxybenzamine is highly specific for its target receptors, the downstream effects of receptor blockade may be more widespread. Ultimately, phenoxybenzamine pretreatment may contribute to vasospasm if this is mediated predominantly by noncatecholamine factors.

Papaverine, a phosphodiesterase inhibitor with a half-life of 100 minutes, is widely used during ITA harvesting to reverse spasm resulting from surgical manipulation. Gentle hydrostatic dilation with papaverine solution $(1 \mathrm{mg} / \mathrm{mL})$ has been advocated for radial artery harvesting. ${ }^{15}$ Our previous work demonstrated that incubation with this concentration of papaverine caused endothelial dysfunction in harvested radial artery. ${ }^{23}$ In this study we therefore used a dose $(0.1$ $\mathrm{mg} / \mathrm{mL}$ ) that was capable of preventing vasoconstriction while maintaining acetylcholine-dependent endothelial function. However, the limited durations of action against both receptor-mediated and receptor-independent vasoconstriction is insufficient to recommend the use of papaverine as an effective topical antispasmodic preparation.

\section{Limitations}

The etiology of radial artery graft vasospasm is likely to be multifactorial, resulting from a combination of surgical injury during harvest, exposure to circulating vasoactive mediators, and preexisting endothelial and medial smooth muscle dysfunction in those with vascular disease states such as diabetes mellitus or hypercholesterolemia. The ex vivo isometric tension model allows the study of vasomotor responses to individual vasoactive mediators in isolation and does not model the complex interactions that may occur in the postoperative patient. We limited the number of vasoconstrictors used to those of clinical importance, fully aware that the use of different agonists might have allowed further characterization of antispasmodic activity and mechanism.

A further limitation of this work is that contractile responses were measured only up to 5 hours after antispasmodic treatment. However, it is clear from the data that the antispasmodic effects of VG solution and papaverine had subsided by this point, whereas the effects of phenoxybenzamine were maintained. In addition, the effect of a continuous circulation eluting topically administered antispasmodic agents from conduits was only crudely modeled in these experiments. In this respect an in vivo model may be more helpful in determining the true durations of action of these agents.

\section{Conclusion}

This study shows that no single topical antispasmodic agent currently fulfills all the criteria necessary to prevent radial artery vasospasm in clinical practice. VG solution is effective against a broad range of vasoconstrictors, but its relatively short duration of action limits its usefulness in the clinical setting. Phenoxybenzamine is a more effective agent to prevent $\alpha$-adrenergic spasm than VG solution or papaverine. Its prolonged duration of action makes it a useful agent in the immediate postoperative period after CABG, especially in patients requiring inotropic support with epinephrine, norepinephrine, or dopamine. However, phenoxybenzamine has little effect on vasoconstriction caused by most other vasoactive mediators. Papaverine, with the shortest duration of action and limited efficacy against relevant vasoconstrictors, is not a useful topical antispasmodic for radial artery conduits. A combination of agents may be more appropriate to combat vasospasm and thereby reduce the likelihood of early graft failure. 


\section{References}

1. Loop FD, Lytle BW, Cosgrove DM, Stewart RW, Goormastic M, Williams GW, et al. Influence of the internal-mammary-artery graft on 10-year survival and other cardiac events. N Engl J Med. 1986;314: 1-6.

2. Taggart DP, D'Amico R, Altman DG. Effect of arterial revascularisation on survival: a systematic review of studies comparing bilateral and single internal mammary arteries. Lancet. 2001;358:870-5.

3. Lytle BW, Blackstone EH, Loop FD, Houghtaling PL, Arnold JH, Akhrass R, et al. Two internal thoracic artery grafts are better than one. J Thorac Cardiovasc Surg. 1999;117:855-72.

4. Taggart DP. The radial artery as a conduit for coronary artery bypass grafting. Heart. 1999;82:409-10.

5. Carpentier A, Guermonprez JL, Deloche A, Frechette C, DuBost C. The aorta-to-coronary radial artery bypass graft. A technique avoiding pathological changes in grafts. Ann Thorac Surg. 1973;16:111-21.

6. Acar C, Jebara VA, Portoghese M, Beyssen B, Pagny JY, Grare P, et al. Revival of the radial artery for coronary artery bypass grafting. Ann Thorac Surg. 1992;54:652-60.

7. Acar C, Ramsheyi A, Pagny JY, Jebara V, Barrier P, Fabiani JN, et al. The radial artery for coronary artery bypass grafting: clinical and angiographic results at five years. J Thorac Cardiovasc Surg. 1998; 116:981-9.

8. Possati G, Gaudino M, Alessandrini F, Luciani N, Glieca F, Trani C, et al. Midterm clinical and angiographic results of radial artery grafts used for myocardial revascularization. J Thorac Cardiovasc Surg. 1998;116:1015-21.

9. van Son JA, Smedts F, Vincent JG, van Lier HJ, Kubat K. Comparative anatomic studies of various arterial conduits for myocardial revascularization. J Thorac Cardiovasc Surg. 1990;99:703-7.

10. Chester AH, Marchbank AJ, Borland JA, Yacoub MH, Taggart DP. Comparison of the morphologic and vascular reactivity of the proximal and distal radial artery. Ann Thorac Surg. 1998;66:1972-7.

11. He GW, Yang CQ. Radial artery has higher receptor-mediated contractility but similar endothelial function compared with mammary artery. Ann Thorac Surg. 1997;63:1346-52.

12. Chardigny C, Jebara VA, Acar C, Descombes JJ, Verbeuren TJ, Carpentier A, et al. Vasoreactivity of the radial artery. Comparison with the internal mammary and gastroepiploic arteries with implications for coronary artery surgery. Circulation. 1993;88(5 Pt 2):II11527.

13. Downing SW, Edmunds LH. Release of vasoactive substances during cardiopulmonary bypass. Ann Thorac Surg. 1992;54:1236-43.

14. He GW, Yang CQ, Starr A. Overview of the nature of vasoconstriction in arterial grafts for coronary operations. Ann Thorac Surg. 1995;59: 676-83.

15. Reyes AT, Frame R, Brodman RF. Technique for harvesting the radial artery as a coronary artery bypass graft. Ann Thorac Surg. 1995;59: 118-26.

16. He GW, Yang CQ. Use of verapamil and nitroglycerin solution in preparation of radial artery for coronary grafting. Ann Thorac Surg. 1996;61:610-4.

17. Minami K, Korner MM, Vyska K, Kleesiek K, Knobl H, Korfer R. Effects of pulsatile perfusion on plasma catecholamine levels and hemodynamics during and after cardiac operations with cardiopulmonary bypass. J Thorac Cardiovasc Surg. 1990;99:82-91.

18. Taylor KM, Brannan JJ, Bain WH, Caves PK, Morton IJ. Role of angiotensin II in the development of peripheral vasoconstriction during cardiopulmonary bypass. Cardiovasc Res. 1979;13:269-73.

19. McAllister RG Jr, Kirsten EB. The pharmacology of verapamil. IV. Kinetic and dynamic effects after single intravenous and oral doses. Clin Pharmacol Ther. 1982;31:418-26.

20. He GW, Rosenfeldt FL, Angus JA. Pharmacological relaxation of the saphenous vein during harvesting for coronary artery bypass grafting. Ann Thorac Surg. 1993;55:1210-7.

21. He GW, Buxton BF, Rosenfeldt FL, Angus JA, Tatoulis J. Pharmacologic dilatation of the internal mammary artery during coronary bypass grafting. J Thorac Cardiovasc Surg. 1994;107:1440-4.

22. Taggart DP, Dipp M, Mussa S, Nye PC. Phenoxybenzamine prevents spasm in radial artery conduits for coronary artery bypass grafting. J Thorac Cardiovasc Surg. 2000;120:815-7.

23. Dipp MA, Nye PC, Taggart DP. Phenoxybenzamine is more effective and less harmful than papaverine in the prevention of radial artery vasospasm. Eur J Cardiothorac Surg. 2001;19:482-6.

24. Harrison WE, Mellor AJ, Clark J, Singer DR. Vasodilator pre-treatment of human radial arteries: comparison of effects of phenoxybenzamine vs papaverine on norepinephrine-induced contraction in vitro. Eur Heart J. 2001;22:2209-16.

25. Velez DA, Morris CD, Muraki S, Budde JM, Otto RN, Zhao ZQ, et al. Brief pretreatment of radial artery conduits with phenoxybenzamine prevents vasoconstriction long term. Ann Thorac Surg. 2001;72:197784.

26. Emilien G, Maloteaux JM, Geurts M, Hoogenberg K, Cragg S. Dopamine receptors-physiological understanding to therapeutic intervention potential. Pharmacol Ther. 1999;84:133-56.

27. Goodfriend TL, Elliott ME, Catt KJ. Angiotensin receptors and their antagonists. N Engl J Med. 1996;334:1649-54.

28. Li HT, Long CS, Gray MO, Rokosh DG, Honbo NY, Karliner JS. Cross talk between angiotensin AT1 and alpha 1-adrenergic receptors: angiotensin II downregulates alpha 1a-adrenergic receptor subtype mRNA and density in neonatal rat cardiac myocytes. Circ Res. 1997; 81:396-403.

29. Hu ZW, Shi XY, Okazaki M, Hoffman BB. Angiotensin II induces transcription and expression of alpha 1-adrenergic receptors in vascular smooth muscle cells. Am J Physiol. 1995;268(3 Pt 2):H1006-14. 